\title{
Art
}

\section{IMAGINAÇÃO, MEMÓRIAS E SENTIMENTOS DE BACKGROUND: A CATARSE DE UM UNIVERSO PARALELO}

\author{
DOI: https://doi.org/10.33871/23580437.2020.7.2.295-312
}

\author{
Dra. Cristiane Weber ${ }^{1}$ \\ Dr. Daniel Conte ${ }^{2}$
}

\begin{abstract}
Resumo: este trabalho se propõe a analisar como o processo criativo na mente de um artista conecta o fazer artístico, as memórias e o afeto envolvidos em uma relação familiar, culminando em uma série de quadros que compõem o acervo do pintor argentino Alejandro Pasquale e sua série de pinturas intituladas Uiverso Paralelo. A ênfase na análise está no papel da imaginação e dos sentimentos de background, não ligados a emoções específicas, neste processo. O referencial teórico passa pelas abordagens relacionadas às bases neurais da criatividade em Abraham (2016), ao processo de criação em Csikszentmihalyi (2008), à evocação de memórias em Izquierdo (2002) e Halbwachs (2003), além dos espaços poéticos de Bachelard (1993), entre outros. O artigo busca contribuir nos estudos da compreensão de como o processo criativo pode servir de catarse e ser fundamental no processo de cura em uma situação de luto vivida por um artista.
\end{abstract}

Palavras-chave: imaginação; memória; catarse; Alejandro Pasquale.

\section{IMAGINATION, MEMORIES AND BACKGROUND FEELINGS: THE CATARSE OF A PARALLEL UNIVERSE}

\begin{abstract}
: this work aims to analyze how the creative process in our mind connects artistic making, memories and affection involved in a family relationship, culminating in a series of paintings that make up the collection of Argentine artist Alejandro Pasquale and his series of paintings entitled Parallel Universe. The emphasis in analysis is on the role of imagination and background feelings, not linked to specific emotions, in this process. The theoretical framework includes approaches related to the neural bases of creativity in Abraham (2016), the creative process in Csikszentmihalyi (2008), the evocation of memories in Izquierdo (2002) and Halbwachs (2003), in addition to Bachelard's poetic spaces (1993), among others. The article seeks to contribute to the study of understanding how the creative process can serve as a catharsis and be fundamental in the healing process in a situation of mourning experienced by an artist.
\end{abstract}

Keywords: imagination; memory; catharsis; Alejandro Pasquale.

1 Currículo Lattes: http://lattes.cnpq.br/9884351444760027. Orcid: https://orcid.org/0000-0002-1761-3263. Universidade Feevale - NH - RS. cristianeweber@feevale.br

2 Currículo Lattes: http://lattes.cnpq.br/1006151597195479. Orcid: https://orcid.org/0000-0002-4251-3299. Universidade Feevale/CNPq - NH - RS. danielconte@feevale.br 
Resumen: este trabajo tiene como objetivo analizar cómo el proceso creativo en nuestra mente conecta la creación artística, los recuerdos y el afecto envueltos en una relación familiar, culminando en una serie de pinturas que componen la colección del artista argentino Alejandro Pasquale y su serie de pinturas titulada Universo Paralelo. El énfasis en el análisis está en el papel de la imaginación y los sentimientos de fondo, no vinculados a emociones específicas, en este proceso. El marco teórico incluye enfoques relacionados con las bases neuronales de la creatividad en Abraham (2016), el proceso creativo en Csikszentmihalyi (2008), la evocación de recuerdos en Izquierdo (2002) y Halbwachs (2003), además de los espacios poéticos de Bachelard (1993), entre otros. El artículo busca contribuir a la comprensión de cómo el proceso creativo puede servir como catarsis y ser fundamental en el proceso de curación en una situación de duelo experimentado por un artista.

Palabras-clave: imaginación; memoria; catarses; Alejandro Pasquale.

\section{Introdução}

Que porções de imaginação e memórias podem levar à composição de um processo criativo quando um indivíduo que amamos deixa abruptamente nosso convívio? Quais as conexões da mente neste processo? Como o luto pode se transformar em algo potenciamente artístico e sensível? Essas foram algumas perguntas lançadas em nossa pesquisa sobre processo criativo ao artista argentino Alejandro Pasquale, que teve a vida marcada por um fato triste e da ordem do sensível no ano de 2013: a perda de um sobrinho que contava, à época, com um ano de idade, em um acidente doméstico.

Para contextualizarmos a catarse envolvida no processo que culmina em uma obra poética, marcada pelo compartilhamento do sensível, é preciso voltar no tempo: em uma noite fria de junho em Buenos Aires, a primeira autora participava de um jantar em confraternização alusiva a um evento científico. Ao adentrar a sala da casa do anfitrião, quadros repousavam nas paredes e outros estavam apenas escorados, com pequenas luminárias que individualizam as telas. Uma das pinturas chamou sua atenção: acima da lareira, óleo sobre tela, um quadro ilustrava o que aparentava ser um menino, segurando dois pássaros em um ramo, com uma enigmática máscara no rosto. "Que queres, menino?", perguntou ela intimamente ao se deparar com o quadro. A resposta foi devolvida com o mesmo olhar. “¿Qué querés vos, conmigo, afinal?”, disse ele em sua imaginação. Silêncio de sua parte. E, de novo, a contemplação da tela (figura 1).

Sua imaginação foi, subitamente, interrompida pelo dono da casa, um médico portenho admirador de uma boa arte. Perguntou-lhe sobre o quadro, se sabia sobre seu significado. Aquela sensação foi dúbia: até então, era apenas o desconhecido a formular teorias em sua mente. Porém, havia a curiosidade. A descoberta iminente. A pesquisadora afirmou ter gostado muito da tela, ao que o médico lhe explicou o contexto de criação: ao perder um sobrinho no trágico acidente, Alejandro Pasquale pintou $D^{* 3}$, o menino (que tem um irmão gêmeo, $M^{*}$ ) em crianças mascaradas, uma pincelada de existência, uma maneira de o manter vivo. Assim, a criança crescia (no sentido do passar dos anos) em suas obras, disse-lhe o colecionador, porém sempre sem rosto, já que sua face de criança mais velha, Alejandro desconhecia. A sensível e instigante história gerou a cursiodade de saber mais - e compreender - essa enigmática obra através do processo criativo que a envolve. O que contavam as pinceladas de amor, saudade e poesia.

Pesquisando em profundidade a obra do artista no repositório Bola de Nieve, dedicado ao acervo online de grandes artistas argentinos, percebemos que houve uma importante modificação na linha de trabalho do pintor. De ilustrações que captavam o cotidiano, Alejandro passou a pintar quadros

\footnotetext{
${ }^{3}$ Nota nossa: os nomes da criança e do irmão gêmeo foram preservados dentro dos princípios éticos e do respeito à família do pintor.
} 
com uma temática mais introspectiva, em uma mudança que coincide com o período marcado pela tragédia familiar. A partir desse fato, em 2013, as ilustrações do artista, geralmente em caneta sobre papel e com uma perspectiva de olhar externo, observando seus modelos, transformaram-se em grandes quadros de óleo sobre tela, onde um realismo mágico (como o próprio artista define) colore não só os primeiros trabalhos após a perda, como também a obra que se estende até hoje.

Neste artigo, em um recorte específico, propomos-nos a apresentar como o processo criativo de Alejandro conectou e, ainda, conecta o fazer artístico, as memórias e o afeto envolvido em uma relação familiar, culminando em uma série de quadros que compõem o acervo do artista. O destaque fica para o papel da imaginação e dos sentimentos de background apresentados em Damasio (1996), não ligados a emoções específicas, mas a um aspecto mais visceral, mais ligado à existência humana. $\mathrm{O}$ referencial teórico passa pelas abordagens relacionadas às bases neurais da criatividade em Abraham (2016), ao processo de criação em Csikszentmihalyi (2008), à evocação de memórias em Izquierdo (2002) e Halbwachs (2003), ademais dos espaços poéticos de Bachelard (1993) e da relação da morte e o luto em Catroga (2010), entre outros. O estudo busca avançar na compreensão de como o processo criativo pode servir de catarse e ser fundamental no processo de cura em uma situação de luto vivida por um artista.

Para saber mais sobre sua criação, foi preciso fazer uma imersão na realidade do artista. Em entrevista concedida em 2018 em seu atelier em Buenos Aires, Alejandro afirmou que não tinha incentivo a práticas artísticas em sua infância. Pelo contrário, utilizava a arte como refúgio em um galpão na propriedade da família, naquela época. Um exemplo que ilustra uma perspectiva contrária a estudos que atribuem o estímulo precoce como maior responsável pelo talento nas artes plásticas. Para Abraham (2016), a abordagem da neurociência cognitiva que se baseava no modelo de que a estimulação dentro do ambiente é percebida pelo organismo que internaliza essa informação (e assim gera uma espécie de resposta com base na contingência da situação) já é um tanto ultrapassada. Enquanto os defensores da interação com o meio enfatizam a participação do corpo com estímulos enriquecedores, outras abordagens em relação a aspectos mais internalizados ficaram praticamente esquecidas nos estudos relacionados à primeira caixa de ferramentas de qualquer artista (ou qualquer outro ser humano): o cérebro. A autora ressalta que "chegou a hora de considerar genuinamente como nosso engajamento nos reinos de imaginação relativamente complicados, esquemáticos e esotéricos com visões dominantes de como a mente funciona" (ABRAHAM, 2016, p. 4.198).

Uma das críticas ao modelo nasce de uma perspectiva mais data base da vida e de nossas relações com o universo psicológico como um todo. A produção de uma obra carrega esse espírito do artista, um modelo de processo criativo ligado ao que foi vivido e ao que se vive enquanto as pinceladas tomam forma e ganham vida. Uma das características centrais da imaginação, ainda, é que esta faculdade nos permite contemplar além do que está no presente, mas nos deslocarmos ao passado e ao que pode se tornar um futuro (ABRAHAM, 2016).

Nos modelos mentais de imaginação propostos pela autora, em combinação a questões filosóficas e neurocientíficas sobre os processos envolvidos no cérebro, a criatividade está englobada no modelo denominado por ela Nova Combinação Baseada no Combinatório, marcado pela abertura, pela novidade e pela descoberta. Neste, a imaginação retira o foco de questões como "o que era" e "o que é" para dar lugar ao "e se" e "o que poderia ser". Este modelo nos parece perfeitamente cabível dentro do contexto do gatilho das obras incluídas na abordagem das crianças mascaradas nos quadros de Alejandro que fomos descobrindo em seu acervo e que apresentamos, em parte, neste artigo. Retratam, de certa forma, um imaginário a respeito de um cenário onde o sobrinho do artista não está morto, mas vivo nas imagens retratadas.

Abraham (2016, p. 4.203) acrescenta que este modelo envolve "a jornada dentro do espaço de possibilidade para ir além do status quo e exige a combinação ou avaliação do conhecimento existente de novas maneiras". Sendo assim, estão envolvidas, nessa perspectiva, a evolução de um problema (estado inicial) para a solução (estado objetivo) por meio de um curso de ação específico (estado de 
operações). Embora possa estar de forma comum mais associada à resolução de um problema específico, a arte também se apropria deste modelo, uma vez que, diante de um fato que lhe provoca o gatilho das pinturas (processo interior de luto e de autoconhecimento), Alejandro busca uma espécie de cura ao seu luto (estado objetivo) por meio da ação de pintar, externando o que lhe acomete em primeira instância.

Enquanto este processo criativo da se forma através de mecanismos variados e complexos, outro entra em ação como um componente essencial no corpus proposto: o sentimento. Se por uma percepção de senso-comum, as pessoas dizem "aja com seu cérebro e não com seu coração", referindo-se a uma separação não embasada cientificamente, cremos ser importante adicionar a esta "caixa de ferramentas" essas peças fundamentais e tão sentimentais. Tudo ocorre, por certo (e como era de se esperar), em nosso cérebro. No entanto, sugere Damásio (1996), os sentimentos estabelecem uma ponte entre os processos racionais e não racionais do órgão. Isso significa que esses processos não estão desconectados da razão, como poderíamos pensar.

Sua perspectiva é de que nem todos os sentimentos estão relacionados com as emoções. O autor explica que todas as emoções originam sentimentos, mas nem todos os sentimentos provêm das emoções. Ainda sobre sua composição, Damásio (1996) relata que existem muitas variedades de sentimentos. A primeira delas se baseia nas emoções, sendo as mais universais e conhecidas a alegria, a tristeza, a cólera, o medo e o nojo e correspondentes a perfis de estado do corpo. Quando o corpo se conforma aos perfis de uma dessas emoções, nos sentimos felizes, tristes, irados, receosos, enojados. Quando os sentimentos estão associados a emoções, a atenção se volta aos sinais do corpo (DAMÁSIO, 1996). Uma segunda variedade de sentimentos, para o teórico, está baseada nas emoções que são variantes das principais e universais, como, por exemplo, a euforia e o êxtase (derivadas da alegria); a melancolia e a ansiedade (variantes da tristeza); ou o pânico e a timidez (variantes do medo). Segundo o autor,

Essa segunda variedade de sentimentos é sintonizada pela experiência quando gradações mais sutis do estado cognitivo são conectadas a variações mais sutis de um estado emocional do corpo. É a ligação entre um conteúdo cognitivo intrincado e uma variação num perfil pré-organizado do estado do corpo que nos permite sentir gradações de remorso, vergonha, vingança [...] (DAMÁSIO, 1996, p. 180).

Por fim, ainda nas variedades de sentimentos, estão os denominados de fundo ou backgrounds. Estes não estão ligados a estados emocionais, e, sim, a estados corporais mais profundos. São os sentimentos da própria vida, da sensação de existir e que ocorrem mais ao longo da vida daqueles que são ligados às emoções. Consoante Damásio (1996, p. 181), "um sentimento de fundo não é o que sentimos ao extravasarmos de alegria ou desanimarmos com um amor perdido [...] ao contrário, ele corresponde aos estados do corpo que ocorrem entre emoções".

Essa percepção contínua do corpo é difícil, pois estamos constantemente distraídos em determinados sentidos, como audição e visão, inclusive por uma questão de sobrevivência. Seria praticamente impossível, no entanto, não termos os sentimentos de fundo, pois a continuidade desses sentimentos se encaixa no fato de o organismo vivo e sua estrutura serem contínuos enquanto houver vida. Nossa identidade individual está ancorada nisso, enquanto uma infinidade de coisas muda em torno do organismo (DAMÁSIO, 1996).

A proposição teórica a respeito dos sentimentos de fundo, ou background, nos parece importante para posterior análise, somada aos processos de criatividade em nosso cérebro. Isso porque, dos sentimentos baseados em emoções (perda do sobrinho) aos sentimentos mais profundos, a respeito da existência humana, Alejandro transporta seu sentir a uma tela com o equilíbrio que nomeia uma das principais pinturas de Universo Paralelo. Externar os sentimentos através da arte, sejam estes 
advindos de emoções manifestadas pelo corpo ou não, insere-o em uma construção pictórica enigmática e persuasiva. Se, naquela noite fria de junho em Buenos Aires, na casa do médico argentino, o quadro questionava e interpelava; entre cada pincelada havia uma profusão de sentimentos que revelavam um devir: estes pássaros continuarão guardando o menino, quer estejam junto ao corpo ou não. Expostos os conceitos de imaginação e de sentimentos que remetem ao visceral, à existência, relato a partir de agora o conceito de flow, que diz respeito à catarse criativa do artista diante de um grande desafio.

Cada exposição de Alejandro carrega aquilo que devemos apreciar e codificar e, até ser lançada aos olhos alheios, apresenta-se como um estado que Csikszentmihalyi (2008) determina como flow. Uma sensação completa de fruição, de devaneios do espírito. Situações que exigem um determinado grau de habilidades diante dos desafios e que, nessa posição, temos escalas de sensações que dizem respeito à magnitude deste desafio e a nossas habilidades diante dele. Um exemplo é a leitura: para ler algo, temos que dominar a língua por uma convenção social, ou seja, devemos ser alfabetizados. Porém, isso, por si só, não é suficiente. Segundo o autor, as habilidades

implicadas em ler incluem não somente a alfabetização, também a capacidade de traduzir as palavras em imagens, de simpatizar com personagens fictícios, de reconhecer contextos culturais e históricos, de antecipar as mudanças da trama, de criticar e avaliar o estilo do autor, etc. (CSIKSZENTMIHALYI, 2008, p. 84)

Alejandro, na mesma entrevista, relatou que começa um quadro sem ter concluído o anterior. Por vezes, trabalha em mais de duas telas simultaneamente. Sua inspiração é, portanto, um convite aos pinceis, à dança da criação, ao desafio de algo novo. No processo de imersão ou flow de Csikszentmihalyi (2008), compreendemos que o tamanho desse desafio depende das habilidades possuídas. $\mathrm{O}$ autor, entretanto, alerta que os desafios não estão somente nas atividades físicas ou na concentração exigida ao lermos um livro. Ela está também na leitura que fazemos do mundo ao nosso redor e nem sempre quando procuramos por algo, na produção de efeitos de sentido que o espaço propicia.

Para Csikszentmihalyi (2008), os desafios são necessários para oferecer uma espécie de catarse a quem produz (neste caso, o artista), um momento que poderia ser classificado como o 'estado transcendente de nossa alma'. Em um de seus estudos, ele conversou com um expert em arte que afirmou que algumas obras oferecem algum tipo de desafio, "e essas são obras que ficam em nossa mente, as mais interessantes" (CSIKSZENTMIHALYI, 2008, p. 85). Pode-se aplicar a mesma teoria ao autor de tão intrigantes pinceladas: a transcendência ocorre quando as altas habilidades do artista encontram seu grau de inspiração e se transformam em imagens poéticas e carregadas de significados. Deste encontro, com o ferramental disponível, vão se delineando as crianças e adolescentes mascarados de Alejandro, em um conjunto de peças complexas e estáticas que levam ao movimento da apreciação, ao sopro leve e intenso da arte.

Com o intuito de ilustrar seu pensamento, diante dessa escala de desafios e habilidades, Csikszentmihalyi (2008) criou o seguinte gráfico (figura 1): 
Figura 1 - Gráfico Flow de Csikszentmihalyi

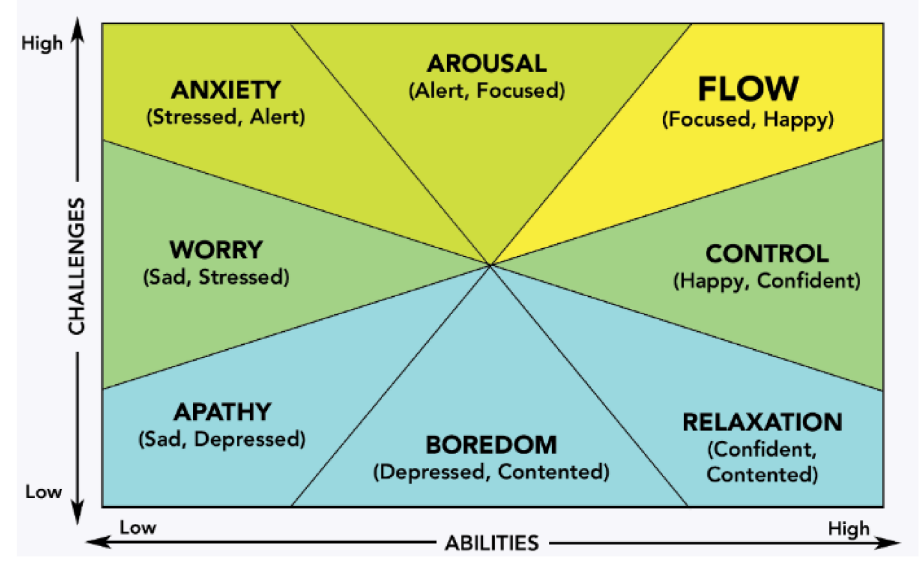

Fonte - Extraída do portal Google Images em 10 fev. 2020

$\mathrm{Na}$ imagem, é possível constatar que esse estado de flow, de fruição, ocorre quando estamos diante de um grande e significativo desafio e aplicamos todas as nossas habilidades diante dele, na tentativa de o elucidarmos ou de o finalizarmos. Façamos aqui um exercício de compreensão ligado ao criar do artista: no caso de Alejandro, um desafio baixo (desenhar uma casa e um personagem simples), com habilidades altas de desenho (sua técnica já está muito além disso) provocariam no artista certo grau de relaxamento (o faz para passar o tempo). Caso suas habilidades fossem baixas para a pintura e o desafio fosse o mesmo, possivelmente a mesma atividade provocaria apatia no artista. Diante de um desafio com sequência de imagens tão imponentes como as produzidas por ele, aplicando suas altas habilidades para a técnica, o argentino chega ao estado de fruição, de flow. Isso é capaz de provocar satisfação, catarse, enfim, tudo o que está envolvido quando constrói sua série a partir de um estado criativo transcendente.

Todo esse processo indizível proposto pela arte em nossa mente, que provoca tal catarse, está contextualizado em um espaço de poética. Espaço, esse, profundo de relações que se formam desde o mais remoto passado, que remontam às mais diversas vivências. Nestes tantos elementos afetivos que queremos elencar neste artigo, moram experiências tão ricas e tão distintas que nem mesmo o cruzamento de todas as artes do mundo seria capaz de abarcar. Seja através da natureza, do nãoretrato ou das roupas das crianças pintadas (como trouxe Alejandro em seu relato) ou através da flor amarela esquecida em um canteiro, do barco de papel encharcado pela chuva ou do cão que foi animal de estimação, tudo remonta ao que somos, ao que vivemos ou sonhamos. Para Bachelard (1993, p. 2), "com a explosão de uma imagem, o passado longínquo ressoa de ecos e já não vemos em que profundezas esses ecos vão repercutir e morrer. Em sua novidade, em sua atividade, a imagem poética tem um ser próprio, um dinamismo próprio". A imagem, portanto, movimenta-se neste jogo infinito de interpretações. Busca em nossas raízes e em nossas memórias as mais singelas e profundas referências. Isso tudo sem movimentos bruscos ou interpeladores.

Voltemos à noite de junho em Buenos Aires, ao quadro estático junto à parede, levemente escorado entre o parapeito da lareira e o concreto retilíneo do pé direito duplo da casa. Fazia morada em um canto da sala, sem qualquer pretensão de ser visto. Foi, porém, visualizado em cada detalhe, transpassando aquela janela de alma pela tinta. Como fez isso? Como um quadro nos chama à dança das interpretações possíveis sem nem antes dizer o que era, a que veio?

Bachelard (1993) apresenta a segunte questão: 
Como esse acontecimento singular e efêmero que é o aparecimento de uma imagem poética singular pode reagir - sem nenhuma preparação - em outras almas, em outros corações, apesar de todas as barreiras do senso comum, de todos os pensamentos sensatos, felizes em sua imobilidade? (BACHELARD, 1993, p. 3).

Para chegar a alguma explicação sobre esse fenômeno, a poética de Bachelard é espaço amplo de embasamento, pois antes de estar em quadro, moldura, linho e cores na casa do colecionador, Equilibrio (nome dado ao quadro) era morada do espaço de espírito de Alejandro. Morada em um terreno fértil e poético do artista, que busca em si mesmo a inspiração para sua construção pictórica. E este terreno se situa em seu mais profundo inconsciente, no espaço da primeira casa. Não a casa física da qual nos lembramos por ter sido morada da infância, seja esta casa de madeira, de tijolos, de qualquer outro material. A primeira casa como primeira morada, inteira de primeiras histórias bastante fragmentadas. Uma casa onde vivemos em nossos sonhos e anseios por um crescimento que parecia distante. Não raro, voltamos a este espaço em nossos sonhos, tal como ali o deixamos. Com os aromas, com as cores e com as proporções de nossa percepção. De acordo com Bachelard (1993, p. 35), "por essa infância permanente, preservamos a poesia do passado. Habitar oniricamente a casa natal é mais que habitá-la pela lembrança; é viver na casa desaparecida tal como ali sonhamos um dia".

A cada retorno a sua primeira morada, pensamos que Alejandro nos dá mão para que retornemos às nossas origens. A cada mão guiada, voltamos aos grupos, concomitantemente. Ora, tais moradas significam o que significam para cada um, individualmente. Começa com essa primeira leitura rápida (um quadro na parede), e depois nos leva de forma mais profunda. Por esse motivo, está a necessidade de uma segunda leitura. Após uma leitura inicial, em forma de esboço, é que vem a obra da leitura (BACHELARD, 1993).

No dia 22 de junho de 2016, alguns dias após o primeiro contato com Equilibrio, a primeira autora recebeu notificação de resposta de seu e-mail trocado com Alejandro. Um pedido para que me explicasse um pouco mais sobre as imagens de "Universo Paralelo" (nome dado à série de pinturas), uma tentativa de compreender seus sentimentos, suas vertentes, sua fonte de inspiração aos traços. Neste, o artista valida a história contada pelo médico e amigo argentino sobre como o incidente com o sobrinho parece ter sido o gatilho para sua arte. Eis o texto ${ }^{4}$ enviado:

Yo realmente no sé si fue intencional o simplemente una maduración que acompañó mi humor en el curso de mi vida/trabajo, pero que sé es que los niños de las máscaras surgieron después de que mi sobrino un año de edad morir en un accidente doméstico.[...] algún tiempo después de que eso sucediera comenzaron a surgir la serie de niños Maskaras, y tal vez la parte más consciente de mí no vio que era un reflejo de mi deseo de compartir momentos con $D^{*}$, pero ciertamente cada niño retratado es parte de mi sobrino, de alguna forma, la creación de nuevos recuerdos a través de ellos. Puntualmente en "Equilibrio" mi trabajo refleja algunos hechos y pasajes de mi vida. Yo tengo una memoria de mi infancia de dos bien-te-vis que salve después de una fuerte tempestad, y que cayeron de su nido en el jardín de mi casa, los cuales alimente durante unas semanas hasta que pudieran volar. Yo estaba con alrededor de 6 o 7 años. Recuerdo claramente que mi madre me explicaba cómo debería cuidar de ellos para mantenerlos vivos. Por otro lado, $D^{*}$ tiene un hermano gemelo $\left(M^{*}\right)$ que ya tiene 4 años de edad, y está creciendo lleno de amor y felicidad. Y tal vez haya un poco de carga emocional al mirar hacia él y, inconscientemente, pensar en cómo sería si $D^{*}$ estuviera vivo, que diría él o los juegos que le podría jugar. Intento responder a estas preguntas a través de mis

\footnotetext{
${ }^{4}$ Conforme e-mail trocado com o artista e resposta recebida em 22 de junho de 2016.
}

R. Inter. Interdisc. Art\&Sensorium, Curitiba, v.7, n.2, p. 295 - 312 Jul.- Dez. 2020 
imágenes. $D^{*}$ era fisicamente muy parecido conmigo cuando era niño, y él era un bebé que, sabe, a pesar de su tierna edad, sabía ver y apreciar la belleza de una puesta de sol, plantas verdes, él amaba la naturaleza en sí.

Percebe-se que as lembranças pessoais de Alejandro, associadas à perda do sobrinho, se misturam nesse espaço de afeto. Essas lembranças são frutos de uma memória que habita sua existência e orbita em tantas outras. Como isso acontece? Para Izquierdo (2002), todos nós somos únicos em nossa construção de memórias. Essa vivência de pouco mais de 400 dias com o sobrinho é um universo puro e particular do artista: somente ele, como indivíduo, carrega na mente e no coração o que essa criança significou em sua vida. Assim como cada um de nós, Alejandro tem suas próprias lembranças. Como explica o autor,

[...] a coleção pessoal de lembranças de cada indivíduo é distinta das demais, é única. Todos recordamos dos nossos pais, mas os pais de cada um de nós foram diferentes. Todos recordamos em geral, vaga, mas prazerosamente, a casa onde passamos nossa primeira infância; mas a infância de uns foi mais feliz que a dos outros [...] (IZQUIERDO, 2002, p. 10)

Essas memórias provêm daquilo que somos e do que vivemos. Ninguém pode reportar aquilo que não viveu, e são essas vivências que se colocam em nosso cérebro. Somos indivíduos formadores de memórias diversas, baseadas naquilo que experimentamos, o que significa que as memórias dos humanos e dos animais provêm do mesmo âmbito: o das experiências (IZQUIERDO, 2002). Tudo pode se moldar nessa outra memória que todos temos a respeito da infância, umas mais felizes, outras nem tanto, ainda assim presentes. Izquierdo (2002, p. 16) ratifica essa categorização quando diz que as memórias são diferentes umas das outras: "umas são mais visuais (a casa da infância); outras, só olfativas (a do perfume da flor); outras, ainda, quase completamente motoras ou musculares (nadar, andar de bicicleta)".

Cremos ser importante abrir um espaço neste estudo para abordar os modos de existência que constituem um espaço único a ser avaliado na arte de Alejandro, fora do escopo que determinamos como real e existente, o que está em nosso plano de percepção. Isso nos ajuda a compreender — ainda mais - como aquele menino do quadro Equilibrio e as demais crianças existem nas obras, dotadas de um próprio sentido de existência; ainda, como são permeadas por diversas memórias que se materializam nas pinturas e no processo criativo do artista, que adotam esse caráter de existência plena. Um existir que se recusa à finitude da vida e à interiorização do desejo de se sentir imortal, esta última proposta por Sigmund Freud. Essa abordagem é necessária para enfatizar o papel do luto pela perda do sobrinho foi transformado na partilha poética do sensível em nosso corpus.

Apreender o sentido do definhamento, ressalta Fernando Catroga (2010), é um dos requisitos necessários para se compreender a tensão entre um futuro que, ainda, não é e um passado que já não existe quando alguém, principalmente, muito próximo, morre. O autor explica que "o morrer, sendo intrínseco à vida, surge como o problema radical que, em vez de ser recalcado, nos pode ensinar a compreender e a saber vivê-la". Tal compreensão aplica-se ao objeto de nossa análise, uma vez que a própria existência - e o fazer da (nova) arte - de Alejandro Pasquale estão ligados por um novo sentido a partir da perda familiar. A morte, em seu caráter semiótico, envolve os discursos que serão sempre uma fala sobre os vivos (CATROGA, 2010).

Este mesmo autor destaca, também, o conceito de metamemória, que se relaciona com as representações que o ser humano faz de suas próprias lembranças, o conhecimento que possui deste fato e como ocorre a filiação ao próprio passado, o que resulta na construção da identidade dos sujeitos. Isso não significa, no entanto, que a memória seja um retrato fiel ou transparente, tal como um espelho, da realidade do passado: trata-se, em verdade, de uma leitura atual do passado acima de 
uma reconstituição fiel. Ao elaborar suas telas, Alejandro busca nessas lembranças a vivência (curta e intensa) do sobrinho, misturando-se a este passado em sua própria infância.

Buscar o passado é constituir uma retrospectiva. Como observa Catroga, toda

[...] retrospectiva tende a expressar-se numa narrativa coerente, que domestica o aleatório, o casual, o efeito perverso do real passado quando este era presente. Pode, assim, perceber-se porque é que a recordação gera uma imagem que é uma mistura complexa de história e de ficção, de verdade factual e de verdade estética, e porque é que já Halbwachs defendia a existência, na narrativa memorial, de uma "lógica em ação", em que o ponto de partida e o ponto de chegada são constituídos pelo próprio evocador (individual ou coletivo) (CATROGA, 2010, p. 167).

A partir do momento em que representa as personagens que se referem à vida do sobrinho, Alejandro transforma o não-ser (a não existência física) em uma imagem suscitada pela memória, em traços que permitem dar ou retomar à existência os que já morreram. Um intento de driblar o infortúnio, a tragédia, a inevitável dor. O que o artista faz com as telas se assemelha, portanto, ao rito de uma fotografia que marca uma lápide, ou um monumento imenso dedicado a quem falaceu. A diferença está na disposição desta homenagem: das muretas e vielas que transcorrem pelo cemitério, temos a transformação da imagem em tela. Consoante Catroga (2010, p. 168), "cada envelope que enforma o cadáver acrescenta uma máscara ao sem-sentido que ele representa, e trai o nosso desejo de parar a putrescência e de alimentar a ficção de que o corpo não está condenado ao desaparecimento". De modo consciente ou inconsciente, o artista argentino dedica as memórias cruzadas pela infância dele próprio e da criança, de forma iconográfica, em imagens que circulam o mundo pela internet ou em exposições itinerantes, deixando um pequeno fragmento de homenagem por onde quer que os quadros passem. Um monumento à criança e ao que ela representou ou, ainda, representa. Conforme Catroga, a palavra latina monumentum deriva da raiz indo-europeia men. O vocábulo exprime uma das funções nucleares do espírito (mens), a memória. "Deste modo, tudo aquilo que pode evocar o passado e perpetuar a recordação - incluindo os próprios atos escritos — é um monumento" (CATROGA, 2010, p. 170). Por fim, o mesmo autor aborda a teoria de que o culto aos, como toda a recordação, também é um diálogo imaginário do sujeito consigo mesmo, no qual participam a razão, a vista e o coração. Para ele,

[...] o território dos mortos funciona, simultaneamente, como um texto objetivador de sonhos escatológicos (transcendentes e/ou memoriais) e como um espaço público e de comunhão, isto é, como um cenário miniaturizado do mundo dos vivos e como um teatro catártico de lutos, bem como de produção e reprodução de memórias, de imaginários e de sociabilidades (CATROGA, 2010, p. 175).

Elencados os conceitos referentes aos sentimentos de fundo, ao fazer criativo em sua concepção ampla, à evocação das memórias e ao luto e morte como propulsores da arte, apresentamos a metodologia deste artigo. Elegemos três quadros do artista e iremos analisar essas pinturas pela ordem da fenomenologia microscópica de Bachelard (1993), que será utilizada para compreender e apontar os elementos das pinturas de forma poética e perceptiva na relação da dor do artista com a manifestação pictórica. A análise parte de uma perspectiva microscópica porque são lá, nos mais profundos detalhes, que se descobrem as menores e importantes significações da obra poética. É na união da imagem e de sua subjetividade com a realidade não completamente constituída que o fenomenólogo encontra um campo de inesgotáveis experiências (BACHELARD, 1993).

Este é também um passeio pela ordem psicológica desse fenômeno. Segundo Bachelard (1993, p. 7), para que seja percebida a ação psicológica de um poema (neste caso, de uma manifestação pictórica 
poética), "teremos, pois, de seguir dois eixos de análise fenomenológica: um que leve às exuberâncias do espírito, outro que conduza às profundezas da alma". De acordo com esse autor, nada nos prepara para a imagem poética: nem a cultura, nem a percepção. Ela é uma transmissão de uma alma para a outra (BACHELARD, 1993). Bachelard complementa que somente a fenomenologia, partida da imagem em uma consciência individual, pode ajudar a medir a amplitude de uma imagem, a força e o sentido dessa manifestação. Toda a transubjetividade da imagem, no entanto, não pode ser determinada definitivamente. Bachelard (1978) apresenta-nos uma analogia ao leitor que estiver diante de um poema:

Para um leitor de poemas, o apelo a uma doutrina que traz o nome, frequentemente mal compreendido, de fenomenologia, corre o risco de não ser entendido. No entanto, fora de toda doutrina, esse apelo é claro: pede-se ao leitor de poemas para não tomar uma imagem como objeto, menos ainda como substituto do objeto, mas perceber-lhe a realidade específica. É preciso para isso associar sistematicamente o ato da consciência criadora ao produto mais fugaz da consciência: a imagem poética (BACHELARD, 1978, p. 185).

Consideramos esta uma tarefa transcendente da alma. Dar à imagem sua atribuição poética, é perceber tudo aquilo, ou parte daquilo que está ali para além de um signo. Significa ir às profundezas de sentimentos, de vivências, de experiências daquele artista. Pois ainda que não se chegue a uma completa constituição, "o fenomenólogo encontra um campo para inúmeras experiências; aproveita observações que podem ser precisas porque são simples, porque "não levam a conseqüências" (BACHELARD, 1978, p. 185).

Apresentamos a seguir nossa análise a partir de três pinturas que representam diferentes momentos do luto de Alejandro: Un Otõno Luz (2014, lápis sobre papel, 51 x $57 \mathrm{~cm})$, feita logo após a morte do menino; Equilibrio (2016, óleo sobre tela, $145 \times 110 \mathrm{~cm}$ ), elaborada dois anos após a perda; e $L a$ Posible Inmensidad de un Charco Luz (2016, óleo sobre tela, $100 \times 100 \mathrm{~cm}$ ), do mesmo período. Estes quadros são analisados por uma ordem fenomenológica e esta análise se entrecruza com parte da entrevista concedida por Alejandro em seu atelier (trechos foram utilizados neste artigo), demonstrando o quanto os sentimentos de fundo ligados à existência e o luto transformado em arte foram expostos em telas que narram dor, sensibilidade e amor pelo menino. Isso nos permitiu conhecer, de perto, não só o processo criativo do artista, como também as conexões estabelecidas entre o fazer e o sentir, principalmente. Por trás de todas as personagens que se colocam como desafiadoras, está uma chave nem tão misteriosa assim: o afeto que nos guia e nos preenche como seres humanos.

\section{Análise}

Acreditamos ser importante abrir esta análise enfatizando que, antes da perda da criança, Alejandro era um artista que observava o mundo a sua volta e o pintava, geralmente em técnica caneta sobre papel, em tons coloridos e vívidos. Um exemplo disso é a obra executada no ano da perda do sobrinho, em 2013. Recebeu o título de Polaroid (caneta sobre papel) (figura 2), mesma técnica do trabalho anterior. 
Figura 2 - Polaroid, por Alejandro Pasquale

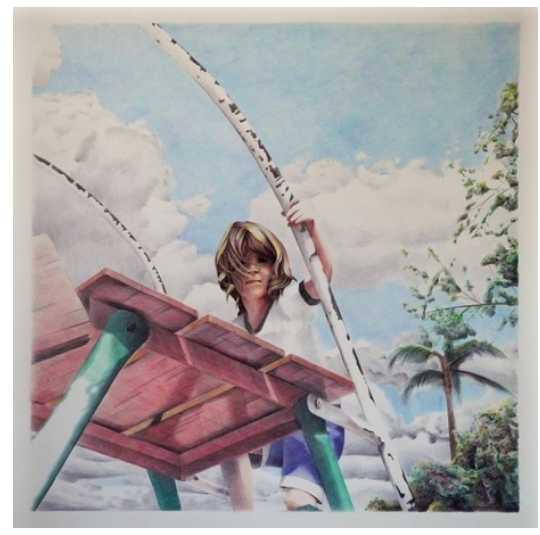

Fonte - Extraída do portal Bola de Nieve em 25 jan. 2020

$\mathrm{Na}$ técnica de Alejandro, muitas cores, ainda que suaves. O detalhamento que o seguirá por toda a jornada como artista é presente: da ferrugem no corrimão aos detalhes de realismo em tudo, principalmente na criança, há um cuidado especial às pequenas nuances da imagem. Até as ranhuras que dão base à madeira da tábua de impulso estão retratadas, assim como a sombra que atravessa os vãos da estrutura. Um desenho de pura observação, onde mais uma vez se encontra uma cena do cotidiano, congelada no tempo e na memória do artista.

\section{Un otoño luz e um giro na realidade}

O outono traz consigo um sopro de ventos frios. Com a estação, vem também um período onde o calor da vida do artista se transforma em um tempo mais gélido. Meses antes, o sobrinho de Alejandro falecia em um acidente doméstico. Sua vida se transforma pela perda. A arte, a técnica e o processo criativo, idem. Dos desenhos de observação, tão cheios de cor e luz, surge o primeiro trabalho, publicado alguns meses depois do ocorrido. Carrega o nome da estação que antecede os dias de inverno: Un otoño luz (figura 3) já se difere da obra anterior pelas cores, pela virada de uma chave, quando surge na imagem uma máscara de papel apresentada à Alejandro na infância, no livro presenteado por uma desconhecida em sua festa de aniversário.

Um pedaço recortado, enigmático, um filtro ao que é atual. 
Figura 3 - "Un otoño luz”, por Alejandro Pasquale

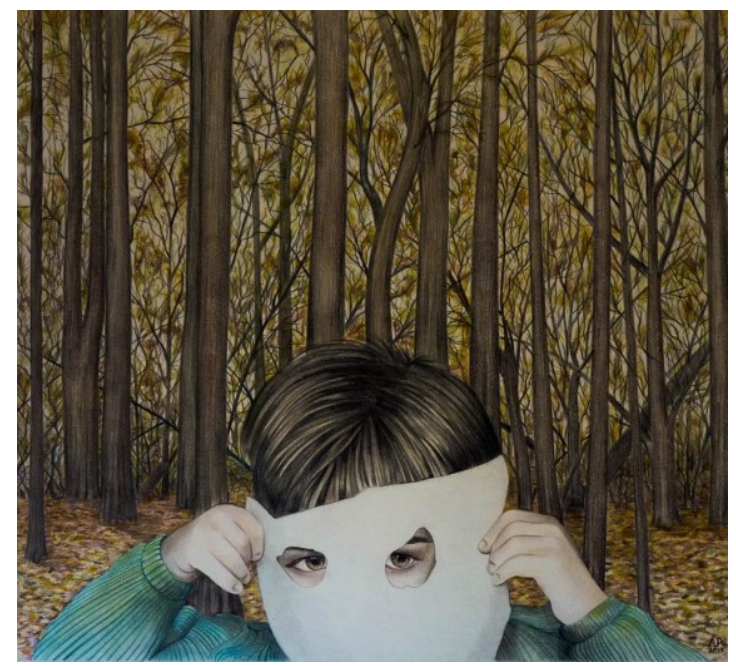

Fonte - Extraída do portal Bola de Nieve em 27 jan. 2020

É possível se esconder da realidade? Ainda mais com um pedaço de papel? O menino da imagem é pequeno, tem seus poucos três ou quatro anos. Não está aos pés do escorregador, nem ao lado do animal de estimação. Encontra-se parado, estático, os cabelos aprumados e bem penteados. Não tem o suor das brincadeiras do verão argentino. A roupa agora não é o leve uniforme escolar: aparece um blusão grosso, de lã penteada, em cores desbotadas. Nas mãos, o menino segura uma máscara mal recortada (com bordas irregulares), que parece ser feita em papel. Há dois pequenos orifícios através dos quais se enxergam os olhos da criança, um pouco desconfiados do que acontece ao redor. $\mathrm{O}$ pequeno tem uma pele em cor fria, quase gélida, com as pontas dos dedos levemente destoantes. Ao fundo, nada de brinquedos da antiga praça: um bosque fechado se ergue de forma opressora. Há inúmeras folhas e galhos, que descansam solenes sobre um infinito de resquícios outonais da natureza. Alguns sobrevivem presos às árvores, em tons de verde engolidos pelo amarelo do pré-descarte. Em troncos finos, os pinheiros se levantam e se acumulam, formando um infinito caminho, o que revela uma paisagem densa. Poucos galhos ou árvores ainda muito finas se esgueiram, apoiando-se nas mais fortes: não sobreviveram, ainda jovens, ao tempo ou à falta de luz do local. Da alegria ao enigma. Em Bachelard, um tanto a mais de significados: a árvore, aqui, tem outra conotação, diferente da anterior. Trata-se de uma devolução ao cosmos motivada pela morte, em uma das tantas concepções da árvore formuladas pelo autor:

Ao nascer, o homem era consagrado ao vegetal, tinha sua árvore pessoal. Era preciso que a morte gozasse da mesma proteção que a vida. Assim recolocado no coração do vegetal, devolvido ao seio vegetante da árvore, o cadáver era entregue ao fogo ou à terra; ou então ficava esperando na folhagem, no cimo das florestas, a dissolução no ar, dissolução ajudada pelos pássaros da Noite, pelos mil fantasmas do Vento. Ou, enfim, mais intimamente, sempre estendido em seu esquife natural, em seu duplo vegetal, em seu sarcófago vivo e devorador, na Árvore - entre dois nós -, ele era entregue à água, abandonado às ondas. (BACHELARD, 1971, p. 247).

O bosque aqui representa um conjunto de árvores que dividem a dor do artista. Choram com ele, naquele assovio característico, a mudança de uma realidade outrora feliz. Servem de esquife à 
existência em matéria do sobrinho, que já não é mais uma realidade. Un otoño luz, enquanto pintura, é precursora de um novo estilo na vida de Alejandro. Difere-se de muitas outras que ele colecionava e compartilhava nas redes. De uma observação apurada sobre o cotidiano alheio, em cenas rotineiras, o artista argentino passa a pintar o imaginado. Um olhar que sai da observação do mundo para uma atenção ao universo anterior, como ele mesmo explica neste trecho da entrevista concedida no atelier em 26 de março de 2018:

Eu trabalhava mirando as crianças, as outras pessoas. Era muita observação. Uma observação externa. E quando aconteceu tudo isso passou a ser uma observação para dentro. São duas formas de trabalhar. É como fazer uma paisagem, só que interna. Creio que esse seja o paralelo, uma observação interna para dentro, para dentro. Fazer observações de mim mesmo. Mostrar um pouco mais quem sou eu, o que eu sinto. Nesse momento eu passei a ser o protagonista da obra e não uma terceira pessoa. Quando aconteceu isso houve um giro muito grande, um giro de imagem, um giro de muitas coisas. Você pode se autoflagelar por coisas que passaram ou transformar isso em algo positivo. Não sei. O corpinho de $\mathrm{D}^{*}$ foi enterrado em um parque, em um caixão. São formas de ver a vida, o mundo, as coisas que nos passam. Eu posso encarar isso como algo horrível que me passou, ou posso aprender com isso. Eu trato de aprender. Nem sempre posso aprender, não sou um "iluminado" (PASQUALE, 2018).

Ao perceber o que o próprio artista relata, já é possível compreender como essa pintura é significativa na mudança do processo criativo. $\mathrm{Na}$ tela, estão outros elementos que apontam para essa transformação: já não há mais a tentativa de um retrato, e o realismo dá lugar a um mundo mais poético e enigmático. Os traços ainda carregam um detalhismo impressionante, mas, em cores mais sombrias. O colorido da luz do sol desaparece, dando lugar a uma luz em tom sépia, provocado pelas próprias nuances do outono. O olhar, antes terno e atencioso, é desviado da "lente" do artista. Não sabemos quem é a criança e nem temos a pretensão de saber. No entanto, fica o questionamento: do que se esconde a personagem criada por Alejandro, escondida no bosque, menos realista e mais mágica? Pode driblar a morte, o outono, os dias frios no horizonte? $\mathrm{O}$ pequeno fica à espreita. E muda a perspectiva do artista em expressar e manifestar suas ideias.

\section{Um equilíbrio na vida, na tela}

É naquele menino que habita a sala do médico colecionador que reside mais uma virada no processo criativo de Alejandro. De esconderijos onde ninguém o encontre, surgirão agora espaços onde a vida interage com aquilo que está sob as máscaras que lhe perpassam o processo de cura pela perda. Se antes a criança mascarada aparecia sozinha, encurralada em um bosque, com a solidão que lhe é possível conceber, desta vez Alejandro tem a companhia de dois pássaros habitando a tela. As espécies em vigília se mostram atentas, dividindo as expectativas pelo devir. O ano é 2016: quase três anos se passaram desde a perda quando surge Equilibrio (figura 4). 
Figura 4 - Equilibrio, por Alejandro Pasquale

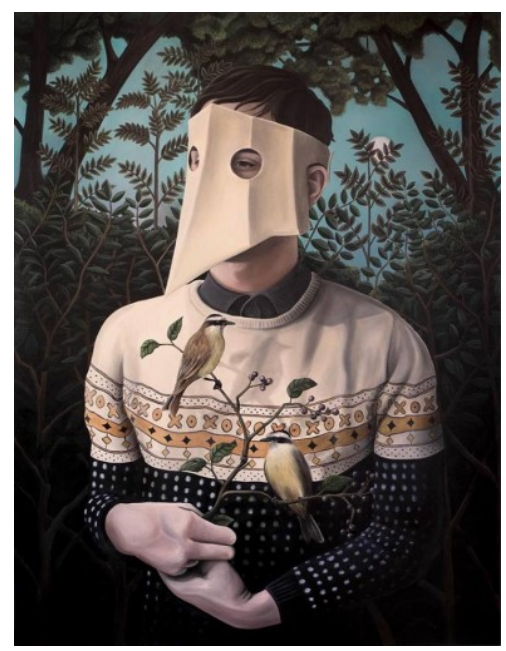

Fonte - Extraída do portal Bola de Nieve em 30 jan.

O menino, apesar de cercado por plantas, parece estar em uma clareira que lhe deixa tranquilo. Sua pele branca, no entanto, transpassa a cor. A pintura de "Equilibrio" demonstra uma tristeza naquele olhar. Um sentimento que traz, ao mesmo tempo, uma carga de proteção e de um poder dado ao artista: o de manter vivo aquele que ele amou. Os pássaros são guardados e guardiões: são espécies de espírito livre, pousam nos galhos em movimentos de vai e vem intermináveis. E não é preciso ser um especialista em botânica para compreender que ali permanecem caso estejam em seus ninhos, caso estejam protegendo seus filhotes. A primeira compreensão é a de que aquelas aves estão protegendo esse menino nesse ninho que é mundo, o mundo onde está agora, não o mundo físico, mas o mundo de onde emerge sua existência, sua permanência poética. Um ninho onde a representação da criança estará acolhida, para onde sempre poderá voltar.

Ainda que respeite esse momento, o do inevitável diante da maior certeza da vida (a morte), Alejandro colocou ali a imagem viva da criança, mas também aplicou à tela elementos de sua própria infância, já que relatou ter ele mesmo resgatado dois pássaros caídos do ninho certa vez. Enquanto o mundo acontece ao seu redor, o menino do quadro parece inerte e protegido, presente e não esquecido. $\mathrm{O}$ próprio nome da produção, aliás, responde ao 'equilíbrio' que pode estar no coração e na mente do artista: um limiar entre a vida e morte.

Elaborados nossos próprios devaneios primeiros, uma das perguntas durante a entrevista concedida em Buenos Aires ao artista foi sobre o que sentiu ao pintar Equilibrio, a que ele respondeu:

[...] na pintura Equilibrio, sou eu com eles ( $D^{*}$ e o irmão $M^{*}$, gêmeos bivitelinos). Essa pintura representa que estou segurando ambos com firmeza, mas com certa dor, e eu sei que eles voam. Pássaros voam. Podem pousar no galho, podem voar. E a verdade é que $\mathrm{D}^{*}$ se foi deste mundo muito cedo. De certa forma eu representei a lua, as estrelas, sempre fui muito ligado a isso. A lua tem a ver com o céu. Estive triste durante muito tempo, foi um momento feio. A pintura serviu para me curar. Meu sobrinho já não está nessa forma (humana), mas passou a ser outras coisas. Passou a ser pintura, a ser recordação, canções que me coloco a escutar.

Os elementos da pintura, portanto, significam pela ternura a partir do conhecimento de que, simbolicamente, um dos gêmeos se levantou rápido do ninho para deixá-lo. No blusão grosso da personagem que representa Alejandro - os dias ainda são frios - a mensagem do "xoxoxo" (beijo e 
abraço, em inglês) é uma expressão de carinho intenso às duas crianças, algo que aparece na técnica do argentino, uma afetividade mais simbolicamente marcada. A pele ainda aparenta estar gélida, embora todo o cenário composto complemente e dê mais leveza à cena. Há mais cores que nas telas anteriores, e estão mais vivas em seus tons, como se demonstrassem uma renovação.

Com a máscara que lhe impõe o silêncio, à frente da clareira que mostra a lua, o artista argentino só sente. Um sentimento de quem ainda lamenta a dor da perda, mas já começa a expressar novas nuances em sua manifestação pictórica, de um realismo cada vez mais, como o próprio Alejandro define, mágico.

\section{Um barquinho de papel no imenso rio da existência}

Dos bosques fechados e de onde surgem interações com a realidade, a imaginação de Alejandro começa a jornada pelo fantástico universo paralelo de sua obra. Serão deixadas de lado, nem que seja por um momento, as solidões impostas pela morte e pela incapacidade da vida diante dos fatos. $\mathrm{O}$ artista agora pinta um mundo ainda mais imaginado, de plena fruição. Uma catarse onde são possíveis fatos impossíveis na realidade: proporções mágicas das personagens, observadores em pequena perspectiva, o desafio à água e ao perigo representado. Em La Posible Inmensidad de un Charco (figura 5), surge uma nova abordagem, um novo olhar. Não é mais a morte que desafia a vida: são as personagens que desdenham do real.

Figura 5 - "La Posible Inmensidad de un Charco", por Alejandro Pasquale

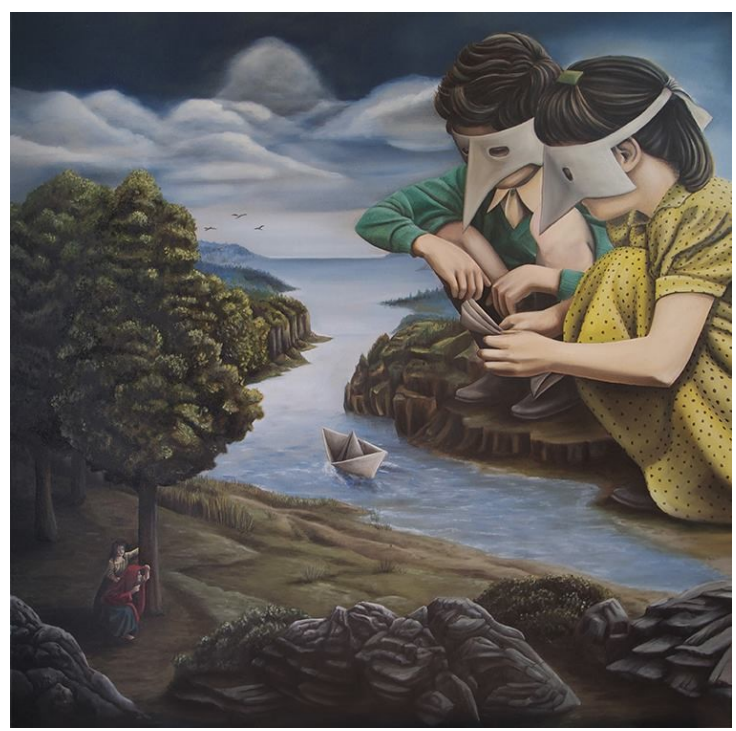

Fonte - Extraído do portal Bola de Nieve em 31 jan. 2020

Da solidão à amizade! Da morte à poética! Os gigantes meninos ou meninas se debruçam diante do rio da vida para desafiar a água que é corrente, como em todo destino. O charco, ou barco, segue pelas águas, enquanto outros são preparados para o mesmo curso. Na margem que é desproporcional ao rio, tudo vira uma brincadeira na qual não é permitido sequer mostrar a identidade. As máscaras que lhe escondem se mostram mais alegres: lembram os bailes de Veneza, à beira do Grande Canal. Ao fundo, no horizonte, pássaros fazem sua jornada para um ponto distante. Vão ao encontro de densas nuvens brancas, outrora obscuras. Nas miniaturas, os detalhes daquilo que assume imensa importância diante do que se agiganta na tela. Como explica Bachelard (1993, p. 179), "do alto de 
sua torre, o filósofo da dominação miniaturiza o universo. Tudo é pequeno porque ele é alto. Ele é alto, logo é grande. A altura de sua morada é uma prova de sua própria grandeza". O contraste sobre aquilo que se mostra engrandecido e a miniaturização também demonstra um poder sobre o mundo, quando Alejandro apresenta a habilidade de apresentá-lo em miniatura.

Para o femonenólogo francês (1993, p. 142), "na miniatura os valores se condensam e se enriquecem. Não basta uma dialética platônica do grande e do pequeno para conhecer as virtudes dinâmicas da miniatura. É preciso ultrapassar a lógica para viver o que há de grande no pequeno". Isso pode ser percebido, por exemplo, nas árvores, antes opressoras e de uma altura que leva ao infinito, e agora revelam-se minúsculas perto das criaturas, que se agigantaram. Já não impõem mais o medo. Pertencem à natureza que não é mais dominadora e nem dominada, apenas integrante da paisagem. Abaixo destas mesmas árvores, duas criaturas procuram se esconder para observar o que acontece: como podem ter crescido tanto? Admiração. Percebem também que está prestes a sair mais um barco, firme ao sabor do vento, das mãos dos que já foram sozinhos e agora se apoiam. Ao redor da paisagem, pedregulhos empilhados formam pequenos rochedos que fortalecem a pintura.

Na poética de Bachelard, mais significados implícitos: a imensidão demonstra um estado puro da alma. De acordo com o autor, esse imenso limiar é uma categoria filosófica do devaneio: “[...] a contemplação da grandeza determina uma atitude tão especial, um estado de alma tão particular, que o devaneio põe o sonhador fora do mundo próximo, diante de um mundo que traz a marca de um infinito" (BACHELARD, 1993 p. 168). Conectando o céu e a terra, a montanha que aparece ao fundo também pode levar a diversas interpretações, tais como o mito da grandeza. "Em suas dilatações e em suas pontas, em sua terra arredondada e em seus rochedos, a montanha é ventre e dentes, devora o céu nebuloso, engole os ossos do temporal e o próprio bronze dos trovões!" (BACHELARD, 1948, 186).

\section{Considerações finais}

Analisando as pinturas do artista e a entrevista concedida por ele em seu atelier, ficou claro o quanto a criatividade de Alejandro Pasquale é intrínseca a um modelo mais internalizado pelo fazer artístico, algo que foge inclusive aos padrões de estímulo que estamos acostumados a ouvir, principalmente, em relação ao que motiva as pessoas a se inserirem no universo da arte com tamanho entusiasmo. Questionando o modelo representacional em psicologia cognitiva, que continua sendo o mais influente ao relacionar as funções psicológicas às funções cerebrais (principalmente nas interações ambientais), Abraham (2016) lembra que o precursor deste processo é o cérebro, mesmo sem estímulos precoces. Caso de Alejandro, que se descobriu artista pelo refúgio de um galpão.

Ao recordar da vivência com o sobrinho, Alejandro transforma as lembranças em uma obra carregada de poética. A criança passa a ter, com isso, um papel inspirador para o tio e artista. Ela se torna um ícone, um norte, um processo de ida e retorno. Uma das perguntas direcionadas a ele, na entrevista no atelier, foi justamente sobre como o sobrinho tem esse papel inspirador na composição criativa. Ao responder à questão, Alejandro ficou, visivelmente, emocionado. Eis um trecho da resposta, em que o artista fala sobre a relação dele com a criança e do dia em que passaram juntos para celebrar o primeiro aniversário do bebê.

Foi muito especial a relação que tive com ele. Não esperava em ter uma relação assim com um sobrinho. O último dia que vi ele foi em seu aniversário de um ano. Ele se apegou a mim e não me largou, não foi com outra pessoa. Nos botamos a caminhar, fazia apenas uma semana que ele estava caminhando. Fomos caminhar no campo, vimos o entardecer e empinamos uma pipa. Fizemos tudo. Vivemos toda uma vida nesta tarde. Me lembro que voltei desse aniversário ainda mais apaixonado 
por ele, falava com todos os meus amigos sobre ele no WhatsApp. Foi fantástico e uma parte da minha vida e vai fazer parte das minhas recordações durante toda a minha vida (PASQUALE, 2018).

Neste dia, Alejandro construiu uma ponte entre suas lembranças da breve convivência com $\mathrm{D}^{*}$, o afago, o afeto, as memórias que se estabeleceriam mais tarde em tinta e linho ${ }^{5}$. Se uma das características centrais da imaginação é a contemplação para além do que está no presente, com a possibilidade de nos deslocarmos ao passado e ao que pode se tornar um futuro, compreende-se como os quadros de Alejandro viajam no tempo através do que foi e do que poderia ter sido, em uma construção simbólica instigante. Por isso, entendemos que o artista substituiu sua dor pela perda física a algo que poderia ter sido, tais como uma criança que habita um universo paralelo, brincando com o cão, superando a derrota para a água, embalando um barco de papel pelo rio. Tudo é possível nessa realidade que não é a dura e real experiência da partida precoce da criança. É um universo, inclusive, que combina muito mais com os pequenos. Onde são o que resolvem ser, para, no outro dia, já serem outra coisa ainda mais divertida.

De um estado inicial, com a perda da criança e uma profunda dor, apresenta-se a solução que carrega um universo paralelo onde tudo é possível através da pintura, da arte, daquilo que se manifesta puramente nas tintas, através de um estado de operações. Na perspectiva fenomenológica da imaginação, somos capazes de construir objetos ou sensações que nunca carregam um aspecto unidimensional, pois cria um quebra-cabeças a quem aprecia, propondo um desafio perceptivo. É o que faz Alejandro com suas pinturas: determina alguns padrões que nunca se apresentam diretamente (ou facilmente), mas criam, enigmaticamente, uma sensação bi, tri, multidimensional.

Entre os mais relevantes enigmas da obra do argentino, a nosso ver, está a presença da máscara. Essa mesma que se apresenta no livro recebido por uma mulher há mais de 30 anos. Esconder o rosto das personagens é a primeira incógnita: o que se representa ali? A criança está feliz, triste, apreensiva? Uma curiosidade imediatamente gerada quando se vê o quadro pela primeira vez.

Sobre esse acessório, Alejandro esclarece que, além de intencional, procura refletir sobre as máscaras que usamos todos os dias em nossa sociedade:

A máscara é como uma espécie de linguagem onde está a metáfora de libertação do imaginário, de uma consciência paralela, que não poderia ser concebida em um universo social. A máscara aparece como isso. A composição do quadro aparece como um universo paralelo que os personagens estão vivendo naquele momento. A máscara é como uma chave, uma porta. É como o frasquinho de Alice no País das Maravilhas, um frasquinho que se bebe e que se aparece em um mundo paralelo, essa é a máscara para um personagem retratado (PASQUALE, 2018).

O rosto coberto pode nos dizer muitas coisas, com a atribuição de incontáveis significados. São esses efeitos de sentido, citados por Bachelard, sobre como sonhamos e rememoramos nossas próprias lembranças e as memórias que são universais, ligadas ao outro. Trata-se deste sonhador que não possui um passado que é somente seu, mas pertencente a todas as "chamas" do mundo, às atribuições de significados propostas por todos nós. Estamos acostumados a ver rostos por todos os lados, principalmente, nas redes sociais. Alejandro desafia, justamente, no processo oposto: escondendo e questionando.

\footnotetext{
${ }^{5}$ Material utilizado nas telas pintadas.
} 
Destes sentimentos de fundo, nasce a obra. Um sentimento que um dia já foi tristeza e dor, mas que, hoje, transformou-se na materialidade pictórica. Surge com a explosão de uma imagem, um passado longínquo que ressoa de ecos e já não sabemos, em profundidade, como vão repercutir e morrer. Essa imagem poética tem um dinamismo próprio, na faísca de uma sensação que se materializa em um quadro, nas exuberâncias do espírito de Alejandro, através da ativação de suas memórias; outro que conduza às profundezas da alma, em sua essência interior.

Em determinado momento da entrevista concedida, Alejandro desviou seu olhar. Estava sorridente e atento a um pássaro que se aproximou na árvore atrás do vidro. "Olha, o pássaro que está aqui nesse quadro! Mira!". Depois, pediu desculpas pela distração. Até mesmo falando de sua arte, Alejandro assume o estado de flow, determinado pelo domínio da técnica de pintura e do tema que tanto lhe agrada. Diante de uma situação tão desafiadora, que exige um determinado grau de habilidades, esse domínio e interesse sugerem essa catarse, um estado transcendente de alma, quando Alejandro tem abstração plena em sua obra, aplicando ali as imagens que melhor compõem esse devaneio. Durante horas, dias ou semanas, ele se debruça sobre o fazer artístico, de tal modo que se desconecta do que está em curso no momento.

Seja com as cores que se transformam com o passar do tempo, seja com as paisagens ainda mais afetivas, tudo se mostra integrante desse universo paralelo através das proporções e da leveza com que interagem, com seus barquinhos de papel. Não há mais seres petrificados e, sim, gestuais. Tons mais claros, mudanças de perspectiva (ligadas ao horizonte), apontam para uma luz que se aproxima, também, da vida do artista. Seus estados emocionais se alteram com o tempo e com a própria pintura. Alejandro segue crescendo e desabrochando novamente para a vida, assim como a imensidão de seu barco pelo rio. Deixa um pouco para trás, no curso natural da vida, aquilo que se assemelhava a uma sombra e que passa a ser um dia claro. Um dia qualquer na vida de uma criança que brinca com a vida, que brinca de viver.

\section{Referências}

ABRAHAM, Ana. The imaginative mind. Human Brain Mapping 37:4197-4211 (2016). Disponível em: <https://onlinelibrary.wiley.com/doi/full/10.1002/hbm.23300>. Acesso em: $12 \mathrm{fev}$. 2020

BACHELARD, Gaston. A poética do espaço. São Paulo: Martins Fontes, 1993.

A filosofia do não; O novo espírito científico; A poética do espaço. São Paulo. Abril Cultural, 1978.

. La poétique de la rêverie. 5. ed. Paris: P.U.F., 1971.

1948.

. La terre et les rêveries de la volonté. Essai sur l'imagination des forces. Paris: José Corti,

BOLA DE NIEVE. Disponível em: <http://www.boladenieve.org.ar/>. Acesso em: 15 mar. 2020.

CATROGA, Fernando. O culto dos mortos como uma poética da ausência. In: ArtCultura, Uberlândia, v. 12, n. 20, p. 163-182, jan.-jun. 2010. Disponível em: $<$ http://www.artcultura.inhis.ufu.br/PDF20/f_catroga_20.pdf $>$. Acesso em: 12 nov. 2018

CSIKSZENTMIHALYI, Mihaly. Flow: the psychology of optimal experience. New York, EUA: Harper Perennial, 200

DAMÁSIO, António. O erro de Descartes: Emoção. Razão e o Cérebro Humano. São Paulo: Companhia das Letras, 1996.

HALBWACHS, Maurice. A memória coletiva. São Paulo: Centauro, 2003.

IZQUIERDO, Iván. Memória - Porto Alegre: Artmed, 2002.

R. Inter. Interdisc. Art\&Sensorium, Curitiba, v.7, n.2, p. 295 - 312 Jul.- Dez. 2020 